\title{
EDITORIAL
}

\section{Género y educación}

\section{Beatriz García \\ Centro de Formación e Investigación Fe y Alegría Coordinadora Nacional}

\begin{abstract}
A pesar de la determinación de la UNESCO de asumir la equidad de género como objetivo global, y de las diversas iniciativas en torno a la erradicación de esta grave problemática social, es indudable que falta mucho por hacer para construir un mundo donde los hombres y mujeres podamos convivir sin discriminaciones.
\end{abstract}

Según cifras de CLADEM (Comité de América Latina y el Caribe para la Defensa de los Derechos de las Mujeres) en su informe "Patrones de violencia contra las mujeres en América Latina y el Caribe" presentado a la ONU en 2014, son alarmantes las altas tasas de feminicidio que se encuentran en la región:

\section{"...el patrón mundial de feminicidios/femicidios refleja que 66 mil mujeres perdieron la vida por el hecho de ser mujeres entre 2004 y 2009, lo que representa el 17\% de to- das las muertes por homicidios (396 mil)7. Más de la mitad de los 25 países con tasas altas y muy altas se encuentran en América Latina y el Caribe: 4 en el Caribe, 4 en Centroa- mérica y 6 en Sudamérica" (CLADEM, 2015, p.4)}

El Observatorio de Igualdad de Género de la CEPAL, en comunicado de prensa web, indica que al menos 1.678 mujeres fueron asesinadas en 2014 por razones de género en 14 países de América Latina y 3 del Caribe (Cepal, 2015). Las cifras no mienten. La inequidad y violencia de género no son un invento o exageración. El rostro más inhumano y dramático es este que señalamos llamado feminicidio, cuya palabra recién entra en la RAE, pero no es el único. Son múltiples las manifestaciones de su instauración en la vida cotidiana: acoso sexual, moral, el maltrato físico, psicológico, la discriminación en el trabajo, el acoso laboral, la falta de responsabilidad paterna en el hogar ... son solo algunas de ellas. 
La discriminación y violencia de género forman parte de la cultura que hemos inventado intrincada por un sistema patriarcal dominante, y lo hace de tal modo que se enraiza en la mente de mujeres y hombres. La discriminación y violencia que subyacen en la inequidad de género se aprende, va pasando de generación en generación; se aprende en la casa, escuela, calle, instituciones, medios de comunicación... porque está instaurada como sistema de relaciones, en el que ni sospechamos ni se pone en duda maneras de actuar, pensar y sentir. Es normal enseñarle a los niños varones que su pene es para conquistar mujeres, a las niñas que deben aprender labores de hogar, que en la escuela las niñas aprenden cocina y los varones futbol. Cosas "pequeñas" que en el tiempo se trasladan a cosas grandes: el hombre manda, la mujer atiende a los hijos, el hombre es "dueño" de la mujer, la mujer obedece. Hay cosas que son indiscutibles, discriminaciones de fondo que no vemos porque están allí aprendidas y forman parte de lo que "siempre hemos hecho".

Avanzar hacia a la equidad implica considerar la educación como factor clave para su erradicación. Si hemos aprendido la discriminación, entonces debemos desaprenderla, para aprender nuevas formas de relación basadas en el respeto verdadero al otro y otra. Los patrones de masculinidad y feminidad, cómo se establecen y regulan las relaciones entre hombres y mujeres, las identidades de género son un asunto que atañe a la educación, pero no solo a la educación de puertas adentro de la escuela, aquella que tiene que ver con el currículo explícito y oculto de centros educativos, con lo que se enseña, cómo se enseña y evalúa; sino a la labor educadora que la sociedad en su conjunto tiene. De manera que educar para la equidad de género es responsabilidad compartida.

El machismo está en el sistema de vida de hombres y mujeres que lo recrean, no son suficientes las políticas, decretos o buenas intenciones de asambleas o convenciones de organismos internacionales, no son suficientes la creación de leyes de defensa de la mujer, ni siquiera mejorar el empleo y condiciones laborales. Es imperativo tocar el corazón y mentes de ciudadanos y ciudadanas que llevan el germen de la inequidad en su seno, reeducar para aprender a vernos iguales y a respetar las diferencias. 
En este primer número de la Revista de Educación "Saberes Andantes" tenemos el privilegio de abordar este tema. Inauguramos una experiencia de verdadero reto para Fe y Alegría Ecuador y su Centro de Formación e Investigación: la edición de una revista en camino a su indexación como espacio de divulgación de conocimientos, propuestas, investigaciones que aporten a la educación. Presentamos artículos que comparten reflexiones e investigaciones realizadas en este marco de búsqueda de nuevas maneras de comprender la feminidad y masculinidad y de visualizar caminos para una perspectiva de género en los sistemas escolares que coadyuve al logro de la equidad. 